\title{
Adaptive behaviour as a factor of psychological health
}

\author{
E. Kuftyak* \\ Kostroma State University, Kostroma, Russia
}

\begin{abstract}
The results of the research revealed that psychologically healthy children more often choose the strategy of passive retreat from difficulties, children with mental health problems are more focused on a destructive emotions expression and "risk group" children use defence of "regression" and "replacement". The psychological defence and copingstrategies contributing to the psychological health state have also been revealed during research. We consider that the received results can be used in the development of evidence-based value orientations and practical recommendations for the healthy personality cultivation.
\end{abstract}

\section{Introduction}

The study of person's adaptation to challenging life situations is one of the topical tasks of modern psychology. Many personal and social problems (addiction, social deviation, fears, impairments of interrelations with others, etc.) have their roots in the impairments of adaptation processes. Obviously, the ability to overcome difficulties is laid as early as in childhood. The development of ability to resolve difficulties and crisis situations defines both the level of adaptation in childhood and the well-being of personality in adulthood.

Modern psychological approaches to stress and adaptation focus on searching uniform mechanisms of human adaptation involving psychological defenses, coping behavior, behavior control, and anticipatory consistency [1].

The theory of defense mechanisms development, elaborated by Cramer, states that a person processes traumatic experiences at both conscious and unconscious levels, which enables to speak of an adaptation process [2]. Cramer assumes that the adaptation process unites psychological defenses and coping behaviour as mechanisms contributing to satisfying an individual need for adaptation to reality. This viewpoint treats defense mechanisms as mechanisms, which change a true perception of reality and protect a person from excessive anxiety caused either by the perception of a troublesome external event or internal destroying mental state. In this aspect, coping behavior is understood as manifest and covert actions performed to reduce or eliminate psychological distress and stress states.

Nikolskaya offers to unite psychological defense mechanisms and coping behavior strategies in a uniform defense system of personality using the analysis [3]. The author identifies four basic levels: somatic-vegetative (physiological), psychomotor (behavioral), level of psychological defense (unconscious psyche) and level of coping behavior

\footnotetext{
${ }^{*}$ Corresponding author: elena.kuftyak@inbox.ru
} 
(consciousness). All these levels are formed sequentially and function simultaneously in adulthood. Nikolskaya argues that a set of defence processes is individual and characterizes the level of personality's adaptation.

Vetrova has conducted the longitude study of a psychological regulation of behaviour in adolescence and early youth, which has revealed that behaviour control, coping behaviour strategies, and psychological defences are closely associated mechanisms of behaviour regulation [4]. It should also be noted that coping behaviour compared to psychological defences is more associated with behaviour control. Psychological defences are more isolated from behaviour control and coping; however, they remain associated with them. The author assumes that coping behaviour strategies and psychological defence mechanisms constitute the continuum of adaptive behaviour based on individual resources of a person. This approach leads the unification of adaptive mechanisms of behaviour (coping-behaviour, psychological defences and behaviour control) in a single space.

The author's earlier research aimed at studying person's uniform defence system in the context of dynamic crises of normative and non-normative family development has revealed that a drawback in the coping repertoire of problem-focused strategies is juxtaposed with a high level of tension of psychological defences [5]. One of the important results of the research is that coping behaviour acts as a stable mechanism of spouses' adaptation in a crisis situation. Psychological defences, in turn, are isolated from behavioural coping strategies; however, they are more associated with coping strategies focused on emotions.

Health characterizes the level of functioning of human organism's systems including the system of mental adaptation, which enables to consider adaptation mechanisms in the spectrum of indices of the psychological health state. The notion "psychological health" introduced in the Russian psychology and practice by Dubrovina enables to reveal a psychological aspect of person's health and relates to personality as a whole [6]. Psychological health is related to the processes, which enable a person to become a mature and an independent subject of activity capable of achieving reference points. Inability to cope with the intensive flow of stresses reduces self-confidence, health resources, and social adaptation. The impairments in the functioning of adaptation processes lead to the development of anxious states, cause neuro-mental and psychosomatic disorders and increase the probability of maladaptive behaviour, especially in children and adolescents.

In clinical psychology, there is a common viewpoint that any somatic impairment is associated with changes in person's mental state. Frequent long-term illnesses in children and adults can be conditioned by a non-constructive system of personality's psychological defence and coping strategies. Insufficient variability and maturity of adaptive mechanisms of behaviour leads to long-term destructive responses to stress and difficulties. Thus, the fixation on infantile defences causes somatic impairments: overstressed immune system increases the level of psychosomatization [7].

We particularly stress that the problems of children's psychological health represent a wider range of manifestations than the sphere of mental disorders in childhood and adolescence. There are some impairments of development, "basic impairments of a prenosological level" [7], which cannot be referred to either psychiatric illnesses or clinically apparent disorders. These impairments are diagnosed by the markers of social impairments or causing considerable damage to others, which indicates internal and external problems in children. This considerably reduces their adjustment and prevents from optimal development at cognitive, emotional, or behavioural levels. 


\section{Materials and methods}

Our study aims at evaluating psychological health and the contribution of psychological defences and coping behaviour to its state. To achieve this goal, we have studied a group of pre-school children from 4 to 6 years (mean age is 5.6 years). The study has involved 86 pre-school children ( 49 boys and 37 girls). The expert assessment of the state of health has enabled to single out three groups of children: "children from the group with impaired psychological health" $(n=25)$, "children from the risk group" $(n=17)$, and "children from the group with preserved psychological health" $(n=24)$.

We have used the following techniques for the expert assessment of the psychological health state.

Assessment of anxiety involving observation (Sear's technique) aimed at defining the level of anxiety in pre-school children [8].

Khukhlaeva's "List of teacher's assessment of child's psychological health" aimed at estimating the state of psychological health indices [8]. We have identified three indices of psychological health in Khukhlaeva's technique (Kuftyak's modification): a personal component, an emotional component, and a social component, which has allowed us to include different meaningful characteristics of health in the study.

The Strengths and Difficulties Questionnaire - SDQ (Goodman) aims at studying common internal and external problems of children from 3 to 17 years [9]. The questionnaire has five scales: emotional symptoms, problems with behaviour, hyperactivity/negligence, problems with peers and pro-social behaviour. The scales of emotional symptoms and problems with peers form a final scale of internalization, while the scales of problems with behaviour and hyperactivity/inattention - a final scale of externalization.

We have estimated psychological defence mechanisms by means of Children Psychological Defence Assessment Map (Peri, Plutchik). The technique enables to evaluate the type of psychological defence. The authors suggest defining eight defence mechanisms (denial, repression, regression, compensation, displacement, projection, reaction formation, and intellectualization) treated as basic in Plutchik's structural theory.

We have studied coping behaviour by means of the Schoolager's Coping Strategies Inventory of Ryan-Wegner adapted by Sirota, Yaltonskiy and modified by Nikolskaya (2000) [3]. We have united 26 coping strategies identified by means of the inventory in 6 basic categories: reflexive withdrawal, passive distraction, discharge; search for spiritual support; destructive emotional expression; active distraction; social contacts (communication) for obtaining support. This technique (unification) has allowed us, first, to make coping strategies used by children closer to the basic styles of personality's coping behaviour and second, to use the methods of mathematical data processing later.

Mathematical-statistical processing of the results of the study is carried out using SPSS v.17 computer packages. It includes a correlation analysis (Spearmen $r$ rank correlation) and the application of non-parameter criteria of evaluating significant differences between non-related samples (Mann-Whitney $U$-test, Kruskal-Wallis $H$ test).

\section{Results and discussion}

The expert assessment by the specialists of pre-school establishments (educators, a psychologist) has enabled to single out three groups of children: "children from the group with impaired psychological health" $(n=25)$, "children from the risk group" $(n=17)$, and "children from the group with preserved psychological health" $(n=24)$. Table 1 represents statistical significance in the evaluation of psychological health. 
Table 1. Indices of psychological health in the groups of children.

\begin{tabular}{|c|c|c|c|c|}
\hline \multirow[t]{2}{*}{$\begin{array}{c}\text { Indices of psychological } \\
\text { health }\end{array}$} & $\begin{array}{l}\text { Children from } \\
\text { the group with } \\
\text { impaired } \\
\text { psychological } \\
\text { health } \\
(n=25)\end{array}$ & $\begin{array}{l}\text { Children } \\
\text { from the } \\
\text { risk group } \\
(n=17)\end{array}$ & $\begin{array}{l}\text { Children } \\
\text { from the } \\
\text { health group } \\
(n=24)\end{array}$ & \multirow[t]{2}{*}{$\begin{array}{l}\text { Kruskal- } \\
\text { Wallis } H \text { test }\end{array}$} \\
\hline & $M(\mathrm{SD})$ & $M(\mathrm{SD})$ & $M(\mathrm{SD})$ & \\
\hline \multicolumn{5}{|l|}{$\begin{array}{l}\text { List of Psychological } \\
\text { Health Assessment }\end{array}$} \\
\hline $\begin{array}{l}\text { General index of } \\
\text { psychological health }\end{array}$ & $42.92(2.78)$ & $\begin{array}{l}31.88 \\
(2.42)\end{array}$ & $14.13(5.28)$ & $57.363 * * *$ \\
\hline Personal component & $19.24(1.2)$ & $\begin{array}{l}13.18 \\
(1.28)\end{array}$ & $6.08(2.63)$ & $57.653 * * *$ \\
\hline Social component & $16.84(1.75)$ & $\begin{array}{l}13.35 \\
(0.78) \\
\end{array}$ & $5.71(2.19)$ & $57.675^{* * *}$ \\
\hline Emotional component & $6.72(1.39)$ & $5.18(1.0)$ & $2.50(1.21)$ & $48.291 * * *$ \\
\hline Sears's scale & $8.72(2.42)$ & $5.88(1.05)$ & $1.62(0.77)$ & $52.268 * * *$ \\
\hline \multicolumn{5}{|l|}{$\begin{array}{l}\text { The Strengths and } \\
\text { Difficulties } \\
\text { Questionnaire }\end{array}$} \\
\hline Internal problems & $8.88(2.6)$ & $5.76(4.70)$ & $2.13(1.19)$ & $37.62 * * *$ \\
\hline Emotional symptoms & $4.04(2.28)$ & $2.76(3.25)$ & $0.08(0.28)$ & $40.86 * * *$ \\
\hline Problems with peers & $4.84(1.14)$ & $3.0(1.70)$ & $2.04(1.08)$ & $32.11 * * *$ \\
\hline External problems & $8.08(2.14)$ & $3.82(3.52)$ & $2.25(1.39)$ & $35.23 * * *$ \\
\hline Problems with behavior & $3.68(1.31)$ & $2.0(1.94)$ & $0.96(0.99)$ & $29.42 * * *$ \\
\hline Hyperactivity & $4.4(1.55)$ & $1.82(1.78)$ & $1.29(0.81)$ & $33.12 * * *$ \\
\hline Prosocial scale & $4.04(1.48)$ & $7.0(1.22)$ & $7.12(1.08)$ & $38.19 * * *$ \\
\hline $\begin{array}{l}\text { General evaluation of } \\
\text { problems }\end{array}$ & $16.96(3.9)$ & $9.59(7.99)$ & $4.38(1.95)$ & $36.44 * * *$ \\
\hline
\end{tabular}

The comparison of data represented in Table 1 clearly indicates that the differences in the components of psychological health lie in personal, social and emotional functioning in all the groups of children and that there are differences between all the groups revealed by the indices of internal problems and emotional symptoms and general number of problems. Children with impairments of mental state have a higher level of anxiety, while a high level of manifestation of personal and social components of mental health indicates children's inability to overcome difficulties, to take initiative, disorderliness, lack of self-assurance, and lack of a pursuit of becoming better.

Children from the risk group report a marked level of anxiety, while in a social component of psychological health, regulative capacities are the most impaired - children are incapable of controlling and overcoming difficulties.

Children from the group with impaired health have worse assessments for emotional deviations described as internalized compared to other groups. They experience anxiety, 
fears, sense of inferiority, helplessness, and reduced mood as well as psychosomatic symptoms. Children from the risk group face emotional problems more rarely; "anxiety" is likely to play an adaptive role in such children and thus provides self-defence behaviour, which enables them to achieve safety in particular social situations.

We have revealed differences in the choice of psychological defences and coping strategies between the groups. Thus, the risk group has been significantly different from the group of impaired health by a weak "regression" defence $(p=0.02)$ and severe "repression" $(p=0.002)$, "compensation" ( $p=0.000)$, and "displacement" $(p=0.001)$ defences as well as a general level of tension of psychological defences $(p=0.05)$. The health group has been significantly different from the risk group and the group with impaired health by the severity of "reaction formation" $(p=0.000)$ and "intellectualization" $(p=0.000)$ defences.

It is found that healthy children usually choose the strategies of passive distraction from difficulties $(p=0.003)$, while children with impaired health usually focus on destructiveemotional expression $(p=0.000)$.

The study has also revealed the correlation interrelations between psychological health and its characteristics and indices of psychological defences and coping behaviour strategies in different groups of children.

In our study, the "displacement" $(R=-0.44, p=0.027)$ and "regression" $(R=-0.39$, $p=0.05)$ mechanisms in the group of children with impaired psychological health have a negative correlation with the components of psychological health, while a "denial" mechanism is positively associated with an emotional component of psychological health $(R=0.42, p=0.037)$. For this group of children, it is shown that the higher is anxiety $(R=-0.74, p=0.000 ; R=-0.58, p=0.003 ; R=-0.71, p=0.000)$, emotional symptoms $(R=-0.50, p=0.011 ; R=-0.72, p=0.000 ; R=-0.47, p=0.018)$ and internal problems $(R=-0.52, p=0.007 ; R=-0.61, p=0.001 ; R=-0.49, p=0.013)$ in children with impaired psychological health, the more rarely they resort to such defence mechanisms as repression, compensation and displacement; the lower is the level of pro-social behaviour $(R=0.43$, $p=0.032$ ), the more rarely they use such defence mechanism as intellectualization.

The discovered relations to these indices support the assumption that descending to the earlier stage of development in behaviour and transformation of a feeling or an object enable children with impaired health to keep their Ego and reduce anxiety, while rejecting everything unpleasant worsens their emotional state. Note also that the ability to act rationally in an emotionally charged situation is a factor of health and contributes to the manifestation of pro-social behaviour.

For children with impaired psychological health, it is shown that the more severe is anxiety $(R=-0.39, p=0.05)$, the lower is the index of choosing emotional-destructive strategies; the higher are the indices of emotional symptoms $(R=-0.453, p=0.023)$, internal problem $(R=-0.55, p=0.005)$ and general evaluation of problems $(R=-0.45, p=$ 0.024 ) of a child, the more rare are the strategies of active distraction. In general, we note that emotional deviation restricts the possibility of resorting to children's behavioural strategies that are socially approved by adults and the most efficient in coping with difficulties.

In the risk group, a defence mechanism "compensation" correlates positively with a social component of health $(R=0.66, p=0.004)$ and hyperactivity $(R=0.49, p=0.045)$, a "denial" mechanism correlates negatively with a social index of health $(R=-0.53, p=$ $0.026)$, problems with peers $(R=-0.57, p=0.017)$, emotional symptoms $(R=-0.64, p=$ $0.005)$ and internal problems $(R=-0.59, p=0.012)$, while "intellectualization" correlates negatively with an emotional component of health $(R=-0.55, p=0.021)$ and a general index of psychological health $(R=-0.39, p=0.05)$. In this group, the index of the "repression" defence mechanism positively correlates with problems with peers $(R=0.62$, $p=0.007)$, problems in behaviour $(R=0.53, p=0.029)$, hyperactivity $(R=0.51, p=0.036)$ 
and internal problems $(R=0.58, p=0.013)$. The index of a "projection" mechanism correlates negatively with the problems with peers $(R=-0.49, p=0.04)$ and internal problems $(R=-0.60, p=0.011)$, and positively with the index of pro-social behaviour $(R=$ $0.52, p=0.032)$.

These correlations indicate that secondary (mature) defences, which do not allow negative information to reach the consciousness and demand an obligatory participation of thinking and waste of energy, reduce energetic background, which leads to child's limited ability to control his behaviour, anxiety and impulsiveness, as well as growing signs of oppositional behaviour. Projecting responsibility for one's mistakes on others and transferring unacceptable feelings and strivings to people around reduces "stresses" turned inwards and behavioural deviations and improves pro-social focus of behaviour.

We have revealed positive correlations between coping strategies and the components of psychological health in the risk group. The strategy of destructive-emotional expression correlates with the index of anxiety $(R=0.44, p=0.08)$, while the strategy of reflexive withdrawal correlates with social $(R=0.48, p=0.05)$ and emotional $(R=0.58, p=0.015)$ components of health, a general index of psychological health $(R=0.59, p=0.012)$, problems in behaviour $(R=0.541, p=0.025)$, hyperactivity $(R=0.55, p=0.021)$ and external problems $(R=0.546, p=0.023)$. For this group, the study has shown the higher is the level of anxiety the more rarely children resort to the strategy of reflexive withdrawal $(R=-0.50, p=0.04)$; the higher is the general index of health (which indicates impaired health), there more rarely they choose the strategy of emotional-destructive expression $(R=-0.48, p=0.05)$; the more severe are the problems in behaviour, the more rare is active distraction $(R=-0.541, p=0.025)$.

The discharge of emotions, frequent tears, and resorting to confession are known to be a characteristic of anxious, restless and inattentive, naughty children [Nikolskaya, Granovskaya, 2000]. On the one hand, the use of these coping strategies enables to overcome internal tension; on the other hand, it causes impairments in the emotional and social aspects of health in such children.

Children with preserved health reveal negative correlations between the mechanism of "reaction formation" and a social index of health $(R=-0.457, p=0.025)$, a general index of psychological health $(R=-0.454, p=0.026)$ and the index of anxiety $(R=-0.41, p=$ $0.04)$. In this group, it has been shown that the lower is the level of anxiety, the more rarely children resort to a "regression" mechanism $(R=0.41, p=0.04)$; the less severe is anxiety, the higher are the values of the index of "repression" mechanism $(R=-0.43, p=0.035)$. For this group of children, it is shown that the less severe are anxiety $(R=0.41, p=0.04)$ and the impairments in the emotional component of health $(R=-0.48, p=0.018)$, the more rarely children choose the strategy of passive distraction.

Thus, resorting to intellectual resources (developing the feeling of subjective control, learning "higher social values", searching for ways to correct or displace) to remove emotional experiences allow healthy children to obtain control in various spheres and ability for strong feelings and experiences.

\section{Conclusions}

1. Children with impaired psychological health use a limited repertoire of psychological defences related to primary (primitive) mechanisms of a psychological defence. Children with preserved mental health are more likely to resort to psychological defences and mostly use defence mechanisms corresponding to a higher level of personal development.

2. Children with impaired psychological health report emotional-destructive coping strategies, which contributes to a negative release of emotions and makes a child more 
vulnerable to an illness. The group of healthy children reports the use of socially desirable coping strategies aimed at constructive exit from a difficult situation, which enables them to get rid of accumulated negative experiences fully or partially.

3. Psychological defences and coping behaviour play a resource or a compensatory role depending on the state of psychological health. In children with impaired health, psychological health is mostly conditioned by primary (primitive) psychological defences, in children from the risk and healthy groups - by rational actions in an emotionally charged situation. Children socially approved behavioural coping strategies are a resource of health in children with impaired psychological health. The strategies of reflexive withdrawal and active distraction are a predictor of children's psychological health.

Our results are of great differential-diagnostic importance; besides, they enable to elaborate differentiated methods of psychological prophylaxis and correction of psychological health impairments.

\section{Limitations}

The study of children's psychological health is based on the expert assessment of specialists who work with children. Therefore, we can get a true picture of health. We investigate the correlation between the indices of psychological health (based on three independent instruments) and psychological defence mechanisms and coping strategies instead of cause and effect relations. Therefore, we can focus on the involvement of adaptation processes into the psychological health.

The reported study was funded by RFBR according to the research project No. 16-36-00038.

\section{References}

1. E. Kuftyak, Psihol. issled 22, 3 (2012)

2. Ph. Cramer, J. of Personality 66, 919 (1998)

3. I. Nikol'skaja, R. Granovskaja, Psychological defense of children (Saint-Petersburg, 2000)

4. I. Vetrova, Tomsk State University J 339, 135 (2010)

5. E. Kuftyak, Med. psihol. Ross 24, 11 (2014)

6. I. Dubrovina, Development of Personality 2, 67 (2015)

7. V. Ananiev, Health Psychology (Saint-Petersburg, 2006)

8. O. Khukhlaeva, Bases of psychological counseling and correction (Moscow, 2011)

9. R. Goodman, H. Slobodskaya, G. Knyazev, Eur. Child and Adol. Psych 14, 28 (2005) 
